\title{
Influências e barreiras ao compartilhamento da informação: uma perspectiva teórica
}

\author{
Alessandra Alves \\ Mestranda da Escola de Ciência da Informação da \\ Universidade Federal de Minas Gerais (UFMG), Belo \\ Horizonte, MG - Brasil.
}

\begin{abstract}
Ricardo Rodrigues Barbosa
Doutor em administração de empresas pela Columbia University, CUNYC, Estados Unidos. Pós doutor pela Faculty of Information Studies da University of Toronto - Canadá. Professor titular do Departamento de Teoria e Gestão da Informação da Escola de Ciência da Informação da Universidade Federal de Minas Gerais - Belo Horizonte, MG - Brasil.
\end{abstract}

\begin{abstract}
Resumo
O interesse pelo compartilhamento da informação em ambientes organizacionais é cada vez maior, já que os investimentos na área podem contribuir para o crescimento e desenvolvimento das empresas. Nesse sentido, por meio de uma revisão da literatura, o artigo identifica e analisa as principais influências e barreiras do compartilhamento da informação em ambientes organizacionais. Com base nessa revisão, refletese a respeito dos principais fatores que influenciam as trocas de informação entre pessoas em contextos organizacionais. As principais influências e barreiras ao compartilhamento da informação são analisadas sob a perspectiva da governança do conhecimento.
\end{abstract}

\section{Palavras-chave}

Cultura informacional. Comportamento informacional. Compartilhamento da informação. Barreiras e influências ao compartilhamento da informação.

\section{Influences and barriers to information sharing: a theoretical perspective}

\begin{abstract}
The interest in information sharing in organization environments is increasing, since investments in such area may contribute to growth and development. In this sense, based on a literature review, the paper identifies and analyzes the major influences and barriers to information sharing in organizations. Based on such review of the literature there is a reflection on the main factors influencing information exchange among individuals in organizational contexts. The main influences and barriers to information sharing are analized from the perspective of knowledge governance.
\end{abstract}

Keywords

Information culture. Information behavior. Information sharing. Barriers and influences to information sharing.

\section{INTRODUÇÃO}

As empresas contemporâneas vêm sofrendo os impactos de uma variedade de mudanças advindas de seu ambiente externo, as quais demandam grande flexibilidade e capacidade de adaptação para garantir sua sobrevivência no mercado. Esse cenário, construído ao longo dos séculos, tem sido reconhecido como "sociedade do conhecimento" (DRUCKER, P. F., 1968) e como "sociedade pósindustrial” (BELL, 1973), dentre outras denominações. A principal característica dessa nova sociedade é o deslocamento das atividades econômicas direcionadas para a produção de valor, as quais têm passado do capital, da terra e da mão de obra para a informação e o conhecimento.

Essas transformações constituem questões muito importantes e presentes no cotidiano da vida humana desde a Idade Média (SIANES, 2005). Essa autora destaca que os problemas relacionados à informação e ao conhecimento, da Idade Média até hoje, são muito semelhantes. Para ela, as diferenças são basicamente relacionadas ao contexto ambiental e aos mecanismos ou instrumentos de busca, organização, armazenamento, disseminação e proteção da informação. Sob essa perspectiva, percebe-se que as principais diferenças entre a atual "sociedade da informação" e as configurações sociais do passado são que a sociedade da informação viabiliza a conectividade instantânea, o compartilhamento em tempo real de informações e as redes de disseminação e troca. Essas possibilidades, que não existiam em passado recente, têm contribuído para interligar múltiplos ambientes de trabalho e promover a disseminação de conteúdos informacionais em níveis cada vez maiores. 
Esse conjunto de mudanças sinaliza que o compartilhamento da informação e do conhecimento destaca-se como um dos principais desafios para os administradores contemporâneos (SMALL\& SAGE, 2006; DYER \& NOBEOKA, 2000; DE LONG \& FHAYER, 2000). De fato, as trocas de informações e conhecimentos são cada vez mais essenciais para o bom funcionamento organizacional, uma vez que seu valor advém não da sua posse, e sim do seu compartilhamento (STEWART, 1998).

Para Hendriks (1999), o compartilhamento da informação pode ser identificado como um dos principais focos da gestão do conhecimento, ou GC, uma vez que esse processo promove a ligação entre o conhecimento individual dos trabalhadores, o chamado conhecimento tácito - em que de fato o conhecimento reside -, e o conhecimento coletivo ou organizacional. Para Nonaka e Takeuchi (1997), o primeiro tipo de conhecimento é o conhecimento pessoal ou tácito, conceitualmente definido como aquele que o indivíduo possui, mas muitas vezes não percebe. Esse saber, adquirido na prática, não é facilmente descrito e transmitido por compreender competências, juízos e intuições. Já o segundo tipo, tratado por Hendriks (1999) como conhecimento organizacional, pode ser entendido como o conhecimento explícito, ou aquele do qual o indivíduo tem consciência de possuir e que, ao contrário do primeiro, é facilmente documentado, registrado e transmitido.

Com base nesses conceitos, verifica-se que as ações de compartilhamento da informação são reconhecidas como um pilar importante dos esforços de GC, mas que, na prática, essas ações muitas vezes não alcançam os objetivos esperados devido a obstáculos de diversas naturezas; de fato, a gama de fatores que influenciam o compartilhamento é variada. Dentre eles, podem-se incluir estruturas organizacionais inadequadas, culturas organizacionais que não incentivam as trocas de informação, ilhamento de setores, ausência de objetivos comuns, além da falta de motivação dos trabalhadores em compartilharem seus conhecimentos (DYER e NOBEOKA, 2000; IPE, 2003; HUYSMAN e WIT, 2004; NOWRK e SIGMUND, 2000).
Levando em conta os elementos apontados anteriormente, o presente artigo tem como principal objetivo refletir sobre os principais fatores que influenciam as trocas de informação entre os indivíduos em contextos organizacionais, representadas neste estudo principalmente nos trabalhos de Ipe (2003), De Long e Fhayer (2000), Huysman e Wit (2004), Dyer e Nobeoka (2000) e Ives, Torrey e Gordon. (2003). Como primeiro passo, serão conceituados termos relevantes para o estudo, como cultura e comportamento informacionais. Em seguida, serão discutidos os conceitos de gestão do conhecimento e de compartilhamento da informação em contextos organizacionais. Sob essa base teórica buscar-se-á explorar e assim compreender a importância desses fatores para os processos de disseminação e troca de informações dentro das empresas.

\section{CULTURA E COMPORTAMENTO INFORMACIONAL}

Ginman (1988) define cultura da informação como a cultura em que

a transformação dos recursos intelectuais é mantida a par da transformação dos recursos materiais. Os recursos primários para este tipo de transformação são diferentes tipos de conhecimento e informação. O resultado alcançado é um produto transformado intelectual que é necessário para as atividades material de funcionar e desenvolver de forma positiva (GINMAN, 1988, citado por CHOO et al., 2008, p. 793).

Já Davenport e Prusak (1998) definem cultura informacional como “(...) o padrão de comportamentos e atitudes que expressam a orientação informacional de uma empresa" (DAVENPORT e PRUSAK, 1998, p.110). Diante dessas visões, verifica-se que a cultura informacional é um conceito amplo e integrado para uma construção conjunta e compartilhada de elementos, valores, normas, crenças e princípios que formam e estruturam a ideologia que sustenta a organização (CHOO, 2008). Assim, a cultura informacional pode ser considerada como o padrão de comportamento que contribui para socialização dos indivíduos. 
Woida e Valentim (2008 p. 08) destacam que, de certa maneira, a cultura informacional impõe ou induz os atores da relação social a atuarem na mesma orientação e objetivos da organização, bem como em relação à produção e uso da informação e do conhecimento. Logo, fica claro que, somente através de uma cultura compartilhada e de uma postura cultural comum a toda a estrutura organizacional, é possível que as empresas obtenham êxito. Nessa linha de raciocínio, Oliver (2003) argumenta que todos os valores e atitudes atribuídos à informação nesses contextos são indicadores da cultura de informação em organizações, e são passíveis de ser moldados pelas interações dentro e entre as diversas camadas da cultura organizacional. Sob esse aspecto, é possível afirmar que "a síntese da cultura de informação e cultura organizacional é uma parte integrante do processo de se tornar uma organização baseada no conhecimento" (CURRY e MOORE, 2003, p. 95).

A definição de cultura informacional é primordial para o entendimento do conceito de comportamento informacional. Isso porque o comportamento informacional diz respeito ao comportamento humano associado a fontes e canais de informação (WILSON, 1997). O autor ressalta que o comportamento informacional engloba a busca ativa e passiva de informação, bem como o uso da informação (WILSON, 2000):

(...) atos físicos e mentais envolvidos na incorporação da informação encontrada na base de conhecimento da pessoa. Pode envolver, portanto, atos físicos como assinalar seções em um texto... bem como atos mentais que envolvem, por exemplo, comparar a informação nova com o conhecimento existente (WILSON, 2000, p. 50).

Por essa vertente, surge novo conceito baseado na busca informacional. Wilson (1997) sugere a busca informacional intencional de informações como o resultado da descoberta e do reconhecimento de alguma necessidade do indivíduo. Ele destaca que o usuário pode procurar respostas às suas necessidades tanto em sistemas formais quanto em outras fontes como, por exemplo, a "troca interpessoal de informação". Todo esse processo tem um só objetivo: satisfazer à necessidade que o indivíduo possui de algum tipo de informação.

As necessidades informacionais são influenciadas, na verdade, por ampla gama de fatores. Conforme as ideias de Leckie, Pettigrew e Sylvain (1996), existem dois fatores que influenciam de maneira decisiva a busca informacional, que são as fontes de informação, ou seja, as referências em que são feitas as buscas, e o próprio conhecimento da informação, entendidos como diretos ou indiretos das fontes, do próprio processo de busca e da informação recuperada.

Wilson (1981) apresenta três conjuntos de barreiras para busca de informações, adotadas também por outros autores: as barreiras pessoais, as sociais ou de papéis relacionados e as barreiras ambientais. Em alguns de seus trabalhos posteriores, Wilson (1997) identifica oito variáveis intervenientes no processo de busca da informação. Esses elementos incluem características pessoais (emocionais, educacionais, demográficas, sociais ou interpessoais), bem como aspectos ambientais, econômicos e mesmo características das fontes e condições de acesso à informação. Não obstante as influências contextuais, o que parece ser determinante na percepção da necessidade, na escolha das fontes de informação e na própria decisão de busca da informação não é a disponibilidade dos recursos e, sim, os processos cognitivos (MARTÍNEZSILVEIRA e ODDONE 2007).

\section{O CONTEXTO TEÓRICO DA GESTÃO DO CONHECIMENTO E DO COMPARTILHAMENTODA INFORMAÇÃO}

Os novos fenômenos relacionados ao conhecimento humano, como a criação de redes sociais e de ambientes digitais interativos, têm contribuído para a transformação de costumes e comportamentos com relação à informação. Nesse novo cenário, destaca-se a importância da informação e do conhecimento na construção de práticas estruturantes e de ferramentas de gestão relevantes para o desenvolvimento das atividades organizacionais em todos os tipos de 
instâncias operacionais, sejam administrativas ou estratégicas. De fato, reconhecer a importância da informação no cotidiano empresarial passou a ser considerado, quiçá, o principal recurso das organizações contemporâneas.

Nessa perspectiva, a gestão do conhecimento surge como um processo multifacetado e de grande complexidade. A amplitude do termo torna-o presente em diversas áreas, como administração de empresas, ciência da computação, comunicação, recursos humanos, biblioteconomia, tecnologia da informação, sistemas da informação e inteligência artificial.

Para Alvarenga Neto (2008), a gestão do conhecimento deve ser compreendida pela metáfora do guarda-chuva. Ele afirma que a GC é um processo que incorpora várias abordagens gerenciais e ferramentas, capaz de ajudar (i) no estabelecimento da gestão estratégica em relação à utilização da informação e do conhecimento (ii) no apoio à promoção da transferência de informações, da inovação, da aprendizagem, da criatividade e (iii) no fortalecimento das competências essenciais da organização. E destaca ainda que a GC deve ser compreendida como a gestão de organizações da Era do Conhecimento, sendo intrínsecas questões relacionadas à mudança e à cultura organizacional. Diante disso, fica claro que o objetivo dos projetos de gestão do conhecimento dentro do ambiente organizacional é o de semear práticas sistematizadas que proporcionem o aumento da capacidade de resposta da empresa perante seus diversos stakeholders para desenvolver inovação, competência, eficácia e conhecimento corporativo (KIM e JU, 2008; DYER e NOBEOKA, 2000; DE LONG e FHAYER, 2000, HOLM, 2001).

Dentre as inúmeras definições de gestão do conhecimento, destacamos, para o objetivo do presente trabalho, a definição do capítulo de gestão do conhecimento da International Federation of Library Associations (IFLA), para quem a GC é um "processo de criação, armazenamento, compartilhamento e re-utilização do conhecimento organizacional para capacitar uma organização a alcançar suas metas e objetivos".

Como se pode constatar, a temática do compartilhamento da informação (ALCARÁ et al.; 2009; DAVENPORT, 1998) ou do conhecimento (IPE, 2003; DYER e NOBEOKA, 2000; DE LONG e FHAYER, 2000) já vem, há algum tempo, ganhando ampla participação nos fóruns e debates que permeiam a agenda da GC. Nesse contexto, diversas terminologias são utilizadas como sinônimas da palavra "compartilhamento" como, por exemplo, transferência de informações, ou de conhecimentos, repasse, disseminação, divulgação, troca e distribuição. Mas apesar de a literatura apresentar diversas opções para designar o termo compartilhamento, adotar-se-á, para fins deste estudo, o termo compartilhamento da informação por acreditar-se que a assimilação e a conversão da informação é mais facilmente articulada, sistematizada e comunicada dentro da estrutura organizacional por meio da linguagem formal, conversas, manuais, expressões, registros formais e informais.

Para Davenport (1998), compartilhamento da informação é "um ato voluntário" que visa colocar as informações à disposição dos outros. Para ele, "O vocábulo compartilhamento implica vontade" por parte do emissor (DAVENPORT, 1998, p.115). Ipe (2003) acrescenta um aspecto relevante a essa definição ao afirmar que o compartilhamento, além disso, implica um ato consciente do indivíduo que participa do intercâmbio de conhecimentos embora ele não tenha a obrigatoriedade de fazêlo. Sob essa mesma ótica, Lin (2007) destaca o compartilhamento como um processo diretamente relacionado à vontade ou ao desejo do indivíduo em comunicar-se diretamente com seus colegas, doar conhecimento e ajudar os outros de forma prazerosa; à consulta ativa aos colegas, que motiva o aprendizado, e ao colecionamento de conhecimento. Essa autora amplia a definição quando ressalta que o compartilhamento da informação deve ser compreendido como uma cultura de interação

${ }^{1}$ Disponível em: <http:/ /www.ifla.org/en/about-the-km-section>. Acesso em 22.08.2010.

Ci. Inf., Brasília, DF, v. 39 n. 2, p.115-128, maio/ago., 2010 
social em que ocorre a troca de conhecimentos, experiências e habilidades.

Segundo Hendriks (1999), o compartilhamento de informações implica a relação entre pelo menos duas partes: uma que é a possuidora do conhecimento e outra que adquire o conhecimento. Nesse processo, a primeira parte pode comunicar o seu conhecimento conscientemente, por sua vontade ou não, de muitas maneiras. Já a outra parte poderia ou não ser habilitada para perceber essas expressões do conhecimento e interpretá-las.

Considerando-se os diversos autores, constata-se que compartilhar informações é basicamente o ato voluntário de tornar um conteúdo disponível aos outros, possibilitando a conversão do conhecimento individual em informações que possam ser entendidas, absorvidas e utilizadas coletivamente (IPE, 2003). Assim, pode-se afirmar que compartilhar não implica ceder a posse do conhecimento ao outro. Ao contrário, dividir abre novas possibilidades para que outros usufruam das mesmas informações junto com aquele que as possui. E essa é uma das grandes dificuldades de realização do processo, vista por Hendriks como um obstáculo que "emana da natureza do conhecimento" (HENDRIKS, 1999, p. 92). Para ele o conhecimento é móvel e portátil, não possuindo limites. Esse fato leva o possuidor do conhecimento a sentir medo de sua ideia ser facilmente copiada depois de compartilhada.

Pode-se afirmar, portanto, que as trocas de informação são facilitadas pela atitude favorável dos indivíduos em fazer trocas, colocando a informação como a principal matéria-prima para a criação de (novos) conhecimentos. Esse processo tende a predominar em ambientes organizacionais que favorecem e possibilitam a contínua conversão entre o conhecimento tácito e o explícito em uma via de mão dupla, como foi defendido pelos autores Nonaka e Takeuchi (1997). A criação do conhecimento apresenta-se como um processo dinâmico de interação que envolve ambos os tipos de conhecimento e a consequente ampliação do saber coletivo. Sob essa perspectiva, percebe-se a extensão do conceito de compartilhamento da informação caracterizado como um processo capaz de promover a integração entre as pessoas com vistas ao aprendizado contínuo, à transmissão mútua de conceitos e habilidades, bem como à geração de novos conhecimentos que promovam a inovação.

Na próxima seção, serão discutidos alguns dos principais fatores que influenciam o compartilhamento da informação em ambientes organizacionais.

\section{BARREIRAS E INFLUÊNCIAS DO COMPARTILHAMENTODA INFORMAÇÃO}

Nas últimas décadas, foram realizados inúmeros estudos que visam a compreender melhor a dinâmica dos processos de troca de informação no ambiente organizacional (KIM e JU, 2008; IPE, 2003; YANG e CHEN, 2007; DE LONG e FHAYER, 2000). Muitos autores defendem que esses processos constituem a chave para o sucesso de um programa de GC, já que esta surgiu como uma ferramenta estratégica para melhorar a produtividade organizacional pela troca e utilização do conhecimento (SPENDER e GRANT, 1996; STEWART, 1998).

Por isso, entender a dinâmica do compartilhamento da informação no ambiente organizacional, no qual atuam seres com interesses e perfis distintos, não é uma tarefa simples. Muitos autores têm investido na realização de pesquisas com o objetivo de compreender e delimitar os fatores que influenciam e determinam as ações de transferência da informação em organizações. Hoje, sabe-se que a falta de processos bem definidos de compartilhamento da informação é uma barreira para a disseminação do conhecimento nas empresas (IPE, 2003). Mas por ser um processo que implica o uso do conhecimento individual em ações junto a um grupo de pessoas, o compartilhamento é mediado por diversos fatores que determinam o sucesso das trocas, da captação e do próprio entendimento dos conteúdos e mensagens. 
A seguir será apresentada uma revisão dos principais fatores que influenciam e determinam o sucesso do compartilhamento da informação em ambientes organizacionais. Para a seleção desses fatores levouse em conta o número de referências detectadas na literatura e o peso que cada autor fornece para cada um dos aspectos citados. Assim, chegou-se à definição de seis itens que, segundo as fontes consultadas, são as principais influências para o compartilhamento da informação dentro de organizações. São elas: a cultura organizacional, a motivação pessoal, a confiança e a reciprocidade, os mecanismos de compartilhamento da informação, o poder e o status e as premiações ou sistemas de recompensa.

\section{Cultura organizacional}

Para Robbins (1999), cultura organizacional é "um sistema de significados partilhados mantidos por seus membros que distingue a organização de outras organizações. Esse sistema de significados partilhados é (...) um conjunto de característicaschave que a organização valoriza" (ROBBINS, 1999, p. 374). Assim, a cultura é a representação da maneira pela qual cada organização aprendeu a lidar em seu ambiente, mas que se constitui, em grande parte, de muitos aspectos mais facilmente percebidos do que visíveis.

Nesse sentido, pode-se afirmar que a cultura é o reflexo perfeito dos valores, das normas e das práticas da organização, em que valores são manifestados por normas que em contrapartida modelam as práticas específicas. A cultura modela a percepção e o comportamento dos indivíduos por meio de um contexto preestabelecido para que ocorram as interações sociais.

Alguns autores acreditam que a cultura organizacional é uma das maiores barreiras que as organizações possuem no processo de desenvolvimento da GC (DE LONG e FHAYER, 2000, YANG e CHEN, 2007, KEONG e AL-HAWAMDEH, 2002). Conforme Ipe (2003), "todos os fatores são influenciados pela cultura” (IPE, 2003, p. 350). Essas afirmações têm como base o fato de que a cultura assume papel fundamental dentro da organização por ser ela responsável por modelar suposições sobre que conhecimento é importante, por controlar os relacionamentos entre os diferentes níveis de conhecimento - organizacional, grupal ou individual - e por criar um contexto para as interações sociais.

É por meio de uma cultura organizacional bem definida que os padrões informais e não escritos de comportamentos aceitáveis e não aceitáveis orientam os colaboradores de uma organização no sentido de agirem para que os objetivos da empresa sejam alcançados. Ou seja, o papel da cultura é primordial para a criação e manutenção do espírito da organização. E é este norteador que definirá como o compartilhamento da informação funcionará, ativando ou não posturas e atitudes adequadas dos colaboradores que vivenciam as rotinas e processos na empresa. Para isso, a organização deve estabelecer com clareza e objetividade quais são seus valores, crenças, políticas e diretrizes para que os colaboradores possam reparti-los em ações e projetos nos quais estejam envolvidos.

A cultura organizacional tem sido identificada como o tema mais relevante dentro das pesquisas de GC e como fator primordial para o sucesso das iniciativas de compartilhamento da informação. Sob esse aspecto, percebe-se que a relação mais próxima entre a cultura organizacional e a gestão do conhecimento está diretamente ligada à cultura informacional, conforme anteriormente assinalado. Isso ocorre porque é a cultura informacional que influencia decisivamente no modo como os produtos de informação (recursos e serviços) são gerenciados (ORNA, 2005).

Assim, à medida que as práticas informacionais são estabelecidas por uma estrutura social de papéis, regras e garantias, elas são consideradas como uma manifestação das normas e valores que a cultura integra em sua estrutura. Sob essa visão, percebe-se que a capacidade cultural de conhecimento e compartilhamento da cultura organizacional é um fator decisivo para o sucesso do compartilhamento das informações (YANG e CHEN, 2007). De fato, estudos como de De 
Long e Fhayer (2000) confirmam que a cultura influencia o comportamento dos indivíduos ,constituindo, assim, ingrediente fundamental para as atividades de $\mathrm{GC}$, as quais envolvem criação, compartilhamento e uso da informação.

\section{Motivação}

Assim como a cultura organizacional, a motivação individual é um assunto complexo e com várias facetas, pesquisado em diversas áreas do conhecimento. Estudos revelam que um dos principais problemas relacionado ao comportamento organizacional é a compreensão do porquê os indivíduos desempenham e comportam-se da maneira como fazem em seu trabalho e em suas organizações (BOWDITCH e BUONO, 1992). Perguntas com o objetivo de compreender o que leva uma pessoa a se dedicar ao máximo em um projeto ou ação mais do que outra, que apresenta um desempenho mínimo, permeiam este tema.

No contexto do presente trabalho, será dado destaque à análise da motivação humana no que diz respeito ao compartilhamento da informação nas organizações. As pessoas não gostam de compartilhar saberes sem ter bons motivos que as levem a isso, o que influencia todo o processo. Ipe ainda destaca que a motivação para o compartilhamento é influenciada pelo poder que o conhecimento compartilhado pode proporcionar, pela reciprocidade das relações de troca, pela recompensa oferecida no ato de participar e pelas oportunidades de compartilhamento que a organização oferece aos indivíduos. Ou seja, a motivação pode ser considerada como o produto entre as características do indivíduo e da situação - e todas as variáveis - que os envolvem.

Em suma, não se pode ignorar a importância da motivação para o compartilhamento da informação. Compreender esses fenômenos e processos constitui tarefa árdua, porém necessária para os gestores das organizações modernas. A devida compreensão dos comportamentos de busca e uso da informação em organizações irá possibilitar a criação de formas adequadas de incentivar os funcionários a colaborar com seus pares e superiores hierárquicos no sentido de contribuir para o desenvolvimento organizacional.

\section{Confiança}

Um ambiente de confiança é um importante requisito para o compartilhamento da informação (KEONG e AL-HAWAMDEH, 2002) e, por isso, tornou-se um dos elementos fundamentais para as trocas informacionais. Por sua vez, a confiança depende da crença na integridade, no caráter e na capacidade de cada um dos elementos envolvidos nas interações pessoais em organizações. E essa relação de confiança entre os membros de uma equipe ou organização leva tempo para ser construída - é fácil de destruir e difícil de reconquistar. Ou seja, o compartilhamento da informação ocorre à medida que existam níveis adequados de confiança entre os indivíduos.

Resumidamente, a decisão de trocar informações é baseada na confiança. $\mathrm{Na}$ ausência da confiança as práticas formais para o compartilhamento $\mathrm{da}$ informação tornam-se insuficientes para encorajar indivíduos a compartilharem seu conhecimento dentro do ambiente de trabalho (ALCARÁ et al., 2009).

\section{Reciprocidade}

Implicitamente ao ato de compartilhar informações, encontra-se o sentimento de reciprocidade, ou seja, a crença de que, ao compartilharem, as pessoas podem vir a receber algo em troca (COHEN, 1998). Assim, verifica-se a reciprocidade como uma das principais condições para o efetivo compartilhamento da informação, uma vez que essa troca é bidirecional. Isso, de fato, já havia sido defendido por Shannon e Weaver (1975) em sua Teoria Matemática da Comunicação. Para esses autores, a informação está presente sempre que um sinal é transmitido de um emissor para um receptor e esse sinal é reenviado para completar o processo de feedback. Neste contexto, o feedback. possibilita a troca efetiva de informações, visto que contribui para reduzir os ruídos no processo. 
Assim, acredita-se que a reciprocidade facilita o compartilhamento da informação e possibilita que os indivíduos agreguem valor pelo que repartem com os outros. A manutenção da reciprocidade nas equipes é vantajosa também por afastar o medo da exploração entre os envolvidos, potencializando as trocas informacionais (ALCARÁ et al., 2009).

\section{Mecanismos de compartilhamento: canais e ferramentas para o relacionamento}

Os canais de comunicação são os meios pelos quais a informação e o conhecimento são comunicados ou transmitidos de um indivíduo para outro, possibilitando as trocas de informação (KEONG e AL-HAWAMDEH, 2002). Para efetivamente funcionar, o compartilhamento da informação necessita que os colaboradores de uma organização tenham acesso a canais, ferramentas, meios e mecanismos adequados. Para Shin (2001), a principal barreira para o compartilhamento da informação é o bloqueio dos canais de comunicação entre o provedor do conhecimento e o receptor. $\mathrm{Na}$ visão desses autores, "os fluxos de conhecimento nas organizações são fundamentalmente dirigidos pelos processos de comunicação e os fluxos de informação" (SHIN et al., 2000, p. 343-344). Outros estudos sugerem que o conhecimento é compartilhado principalmente por meio de canais informais de relacionamento e aprendizagem. É pela comunicação face a face que muitas ações são desencadeadas e podem resultar em um processo no que os indivíduos se aproximam e criam hábitos comuns (BROWN e DUGUID, 1991).

Outro aspecto que merece destaque é a influência das tecnologias da informação e da comunicação (TICs) $^{2}$ nos processos de GC e para alavancar o compartilhamento das informações. É fato que a tecnologia está altamente presente e atuante nas

\footnotetext{
${ }^{2}$ As tecnologias da informação e da comunicação (TICs) são "o conjunto de tecnologias que permite a aquisição, a produção, o armazenamento, o tratamento, a comunicação, o registro e a apresentação de informações, de forma rápida e em grande quantidade, em forma de voz, imagens e dados contidos em sinais de natureza acústica, ótica ou eletromagnética" (PINTO e CABRITA, 2005, p. 498).
}

rotinas e atividades do cotidiano da sociedade moderna. Mas quando a tecnologia não é aceita pelos colaboradores da organização, eles deixam de lado a ferramenta, independentemente das punições ou normas impostas. Esses fenômenos destacam a importância de ferramentas adequadas ao uso para possibilitar a participação efetiva das pessoas nos processos de colaboração e compartilhamento (HUYSMAN e WIT, 2004).

\section{Poder e status}

Dentre os fatores motivacionais internos que influenciam o compartilhamento da informação destaca-se o sentimento de que conbecimento é poder. Esse sentimento, amplamente disseminado na nossa cultura, muitas vezes materializa-se na forma de obstáculos ao compartilhamento da informação (ALCARÁ et al., 2009). O sentimento de poder, advindo da posse do conhecimento, garante ao possuidor uma sensação de diferenciação e superioridade em relação aos demais. Observa-se que, na verdade, "quanto mais o compartilhamento é feito mais há a redução do valor do conhecimento individual" (HALL, 2001, p.140). Assim, a relutância em compartilhar é resultado de comportamento inseguro e da incerteza de alguns.

O status, apesar de se diferenciar do poder, está intimamente relacionado a ele. No que diz respeito a esse fator, Nowak e Sigmund (2000) salientam que o ser humano tem obsessão pela reputação, pelo status adquirido ou o que poderá vir a alcançar em uma comunidade ou em um círculo social no qual está inserido. Segundo eles, "o status pode ser um fator implícito para o compartilhamento de informações, porquanto este poderá ser visto com bons olhos pelos demais membros da comunidade" (NOWAK \& SIGMUND, 2000, p.142).

Acredita-se que, com o advento da sociedade da informação, o valor associado ao poder e ao status esteja sendo ultrapassado e que o verdadeiro poder das organizações modernas esteja se concentrando na sua capacidade de promover interatividade e conectividade entre seus membros.

Ci. Inf., Brasília, DF, v. 39 n. 2, p.115-128, maio/ago., 2010 


\section{Premiações ou sistemas de recompensa}

O compartilhamento da informação, conforme defendido neste estudo, pressupõe que esse comportamento seja uma ação voluntária. No entanto, esse enfoque não implica que as organizações não possam e nem devam investir em programas ou ações que estabeleçam recompensas pela participação ativa nas trocas informacionais no ambiente corporativo. O tempo e a energia das pessoas são limitados e elas vão fazer o que acreditam que lhes dará um retorno favorável (COHEN, 1998). Alguns autores argumentam que, explicitamente, as organizações deveriam oferecer reembolsos, premiações ou alguma forma de reconhecimento para os indivíduos que se dedicam ao compartilhamento da informação em suas atividades.

Uma forma de recompensa é a progressão na carreira, que pode estar ligada a diversos fatores, incluindo o grau em que os sujeitos acumulam ou compartilham seus conhecimentos. Assim, quanto mais as pessoas compartilham, mais chances elas têm de progredir dentro dos níveis hierárquicos da organização ou de angariar benefícios para o seu desenvolvimento profissional.

Apoiar o colaborador na construção da sua boa reputação por meio do reconhecimento de seus parceiros de trabalho também é uma estratégia de recompensa. Esse reforço está diretamente ligado às ambições individuais e os próprios indivíduos que reconhecem isso tornam-se mais susceptíveis de serem partícipes do processo solidário (HALL, 2001). Nesse sentido, uma possibilidade de recompensa é conseguir que o funcionário sinta-se satisfeito com as suas ações de troca de informações e reconhecido pelo bom trabalho que executa.

\section{Natureza do conhecimento}

Uma das dificuldades em levar as pessoas a compartilhar informações tem raízes na natureza do próprio conhecimento. Como já afirmado, o conhecimento nas organizações pode apresentarse sob a forma tácita ou explícita. Esses vários tipos de conhecimento têm sido valorizados diferentemente dentro das organizações. Em especial, a valorização depende do grau em que são codificáveis, transmissíveis, adquiridos e acumulados, bem como seu potencial em ser coletados e distribuídos (LAM, 2000).

Independentemente do tipo, fica claro que tanto o conhecimento tácito quanto o explícito têm grande impacto para o que e como os indivíduos compartilham as informações. Desse modo, a única distinção será a forma de compartilhar, já que, o conhecimento tácito é de difícil transmissão, o que acarreta a necessidade de se pensar estrategicamente no que, como, quando e porquê fazer a transferência do conhecimento a fim de torná-la efetiva em sua proposta e objetivo (IPE, 2003).

\section{Tecnologia}

Com os avanços rápidos e constantes da tecnologia, o compartilhamento do conhecimento tornou-se mais viável tanto para diminuir o tempo gasto em determinadas tarefas quanto para reduzir custos de produção e de manutenção nas empresas (KEONG e AL-HAWAMDEH, 2002, YANG e CHEN, 2007). Atualmente, a tecnologia assume a posição de requisito básico para o efetivo e bem-sucedido compartilhamento das informações no ambiente organizacional.

Segundo Yang e Chen (2007), a capacidade de conhecimento técnico e a própria tecnologia disponibilizada para efetuar as trocas de informação pode ser um fator inibidor crítico, quando uma empresa implementa um programa desse tipo. Segundo esses autores, isso influencia direta e indiretamente o processo com o aumento da velocidade das trocas e da redução dos custos, do tempo e das distâncias dentro das empresas. Mas na ausência das devidas capacidades para utilizar efetivamente o ferramental tecnológico, os recursos de TICs são inúteis. Keong e Al-Hawamdeh (2002) definem essa situação como "tecnofobia". Para eles, alguns indivíduos ainda se sentem intimidados pelos computadores. Nesse sentido, destaca-se a necessidade da adoção de interfaces mais amigáveis e intuitivas, elaboração de treinamentos e cursos de formação e na estruturação de um 
suporte técnico robusto para ajudar os trabalhadores a utilizarem com mais eficiência as ferramentas de tecnologia disponíveis nas empresas.

A tabela 1 sintetiza o conjunto de barreiras e influências ao compartilhamento da informação e do conhecimento em organizações, bem como os principais autores que contribuíram para essa análise.

Uma vez identificadas as barreiras e influências ao compartilhamento da informação, faz-se necessário dimensioná-las sob o ponto de vista da organização. Para isso, foram analisados diversos estudos que têm como proposta o desenvolvimento de modelos que incorporam esses fatores. Destacamos três desses trabalhos, os quais são considerados por estes autores como os mais relevantes.

Inicialmente, cita-se o trabalho de Keong e AlHawamdeh (2002), no qual classificam os fatores que influenciam o compartilhamento em três dimensões: uma relativa ao nível organizacional

TABELA 1

Barreiras e influências do compartilhamento da informação e as referências de cada tema.

\begin{tabular}{|c|c|}
\hline Fatores que influenciam o compartilhamento & Referências \\
\hline Cultura organizacional & $\begin{array}{l}\text { De Long e Fhayer (2000); Yang e Chen } \\
\text { (2007), Keong e Al-Hawamdeh (2002); Hall } \\
\text { (2001); Ipe (2003); Robbins (1999); Orna } \\
\text { (2005). }\end{array}$ \\
\hline Motivação do indivíduo & $\begin{array}{l}\text { Bowditch e Buono (1992); Dyer e Nobeoka } \\
\text { (2000); Ipe (2003); Steinel et al. (2010). }\end{array}$ \\
\hline Confiança & $\begin{array}{l}\text { Alcará et al. (2009); Keong e Al-Hawamdeh, } \\
\text { (2002). }\end{array}$ \\
\hline Reciprocidade & $\begin{array}{l}\text { Alcará et al. (2009); Cohen (1998); Shannon } \\
\text { e Weaver (1975). }\end{array}$ \\
\hline $\begin{array}{l}\text { Mecanismos de compartilhamento: canais e } \\
\text { ferramentas de relacionamento }\end{array}$ & $\begin{array}{l}\text { Brown e Duguid (1991); Huysman e Wit } \\
\text { (2004); Shin et al. (2000); Keong e Al- } \\
\text { Hawamdeh, (2002). }\end{array}$ \\
\hline Poder e status & $\begin{array}{l}\text { Alcará et al. (2009); Hall (2001 Nowark e } \\
\text { Sigmund (2000). }\end{array}$ \\
\hline Premiações ou sistemas de recompensa & Cohen (1998); Hall (2001). \\
\hline Natureza do conhecimento & $\begin{array}{l}\text { Keong e Al-Hawamdeh, (2002); Lam } \\
\text { (2000); Ipe (2003). }\end{array}$ \\
\hline Tecnologia & $\begin{array}{l}\text { Yang e Chen (2007), Keong e Al- } \\
\text { Hawamdeh (2002). }\end{array}$ \\
\hline
\end{tabular}

Fonte: Elaborado pelos autores. em nível individual (motivação, experiências pessoais etc.) e a terceira como o nível ou natureza do conhecimento (tácito ou explícito, articulado

No segundo estudo, desenvolvido por Kim e $\mathrm{Ju}$ (2008), eles fazem a distinção dos fatores em termos relacionais, como a confiança, por exemplo, e estruturais, como os sistemas de premiações ou os canais de comunicação. Por último, tem-se o trabalho de Ives, Torrey e Gordon (2003), no qual se desenvolve um "modelo de desempenho humano", que adota uma classificação simplificada, organizando os fatores como individuais ou organizacionais apenas.

Com base na classificação proposta por Ives, a tabela 2 situa cada fator citado anteriormente. Os fatores organizacionais são de responsabilidade da organização como forma de estruturar e fornecer subsídios para a ação individual ou coletiva. Já os ou não). 
fatores individuais dependem de cada pessoa, da sua percepção, de suas experiências prévias, de suas características e tendências.

Com base no que se argumentou ao longo do presente trabalho e levando-se em conta a classificação apresentada na tabela 2 , percebe-se que os fatores individuais do compartilhamento da informação e do conhecimento são amplamente influenciados pelos fatores organizacionais, principalmente da cultura organizacional, que se caracteriza como um dos maiores influenciadores das ações compartilhadas. A partir da estrutura da cultura organizacional, o sujeito passará a sentir e a agir de acordo com o que é permitido e aceito no contexto organizacional. Isso ocorre devido à necessidade de ele se sentir parte de algo, pertencente a um grupo que o aceita e respeita. Logo, a cultura organizacional influencia as formas de agir e reagir dentro do seu meio, afetando os impulsos motivacionais e os sentimentos de reciprocidade, confiança, de poder e status.

Com base nesses elementos, vislumbra-se a possibilidade de que uma cultura organizacional aberta, que incentive o compartilhamento da informação solidifique conceitos e valores que favoreçam o comportamento colaborativo e participativo, poderá reduzir os impulsos egoístas e a individualidade excessiva.

\section{TABELA 2}

\section{Categorização das barreiras e influências ao compartilhamento da informação}

\begin{tabular}{l|l}
\hline Organizacional & Individual \\
\hline $\begin{array}{l}\text { Cultura organizacional } \\
\begin{array}{l}\text { Mecanismos de } \\
\text { fompartilhamento: canais e } \\
\text { ferramentas de relacionamento }\end{array}\end{array}$ & Motivação do indivíduo \\
\hline $\begin{array}{l}\text { Premiações ou sistemas de } \\
\text { recompensa }\end{array}$ & Reciprocidade \\
\hline $\begin{array}{l}\text { Tecnologia } \\
\text { Natureza do conhecimento }\end{array}$ & Poder e status \\
\hline
\end{tabular}

Fonte: Elaborado pelos autores.

Ci. Inf., Brasília, DF, v. 39 n. 2, p.115-128, maio/ago., 2010
Esse princípio pode ser confirmado por Foss (2007), para quem os processos de criação, manutenção e compartilhamento da informação podem ser influenciados e dirigidos com a implantação de mecanismos de governança do conhecimento ${ }^{3}$, os quais envolvem o uso e controle adequados da estrutura organizacional, de organogramas de trabalho, dos sistemas de recompensa, dos sistemas de informação, dos procedimentos operacionais padrão e de outros mecanismos de coordenação.

Assim, acredita-se que a abordagem de governança do conhecimento, além de seguir o caminho proposto pela administração e pela economia organizacional, deve incorporar em seu escopo fenômenos motivacionais e cognitivos associados à produção e ao compartilhamento do conhecimento.

\section{CONSIDERAÇÕES FINAIS}

Os argumentos apresentados sugerem reflexões a respeito da gestão da informação e do conhecimento na sociedade atual. Dentre essas reflexões, que permeiam o estudo das influências e barreiras nas ações de compartilhamento de informação entre indivíduos, está a certeza de que o uso adequado da informação e do processo de trocas podem ser considerados como um dos principais pilares do sucesso organizacional. E, por consequência, a principal função da GC talvez seja tornar os conhecimentos produtivos e funcionais para quem necessita deles. É essa gestão centrada e eficaz da informação e do conhecimento que irá possibilitar que as organizações se tornem mais competitivas, eficazes e, até mesmo, mais rentáveis.

Por isso, são necessários mais estudos e pesquisas que busquem o entendimento e a compreensão dos fatores que influenciam o compartilhamento da informação como forma de incrementar as

\footnotetext{
${ }^{3}$ Neste estudo, Foss (2007) define "abordagem de governança do conhecimento" como "uma tentativa constante de descobrir como as transações de conhecimento - as quais diferem em suas características e mecanismos de governança - que diferem em relação a como lidar com eles transacionais problemas - são encontrados, usando a eficiência econômica como a princípio explicativo" (FOSS, 2007, p. 29-30).
} 
potencialidades informacionais do ambiente corporativo. Nesse contexto, o compartilhamento da informação constitui um tipo especial de interação social que possibilita a construção de organizações mais flexíveis, ágeis e inteligentes, bem como relações mais abertas e confiáveis, as quais irão contribuir para uma cultura informacional que valorize processos participativos e livres de imposições e interesses individualistas. Nesse sentido, acredita-se que as formas colaborativas de produção e uso da informação contenham em si forte potencial de novas formas de organização do trabalho.

Assim, podemos considerar que compartilhar a informação é, ao mesmo tempo, parte do processo de produção e seu principal produto. Atualmente, não se pode negar a centralidade da informação nos processos de produção econômica e social da sociedade pós-industrial e pós-moderna. A informação também pode funcionar como ferramenta importante de emancipação humana e social. A cooperação e a colaboração no trabalho aparecem como condição e resultado das formas atuais de produção econômica.

Para assegurar informações e conhecimentos realmente vantajosos, as empresas devem ser capazes de identificar pontos para o aperfeiçoamento dos processos de compartilhamento das informações. Além disso, é fundamental o desenvolvimento de uma cultura informacional que possibilite: a) o surgimento e a manutenção de padrões de comportamento perante a informação e seus fenômenos, b) a interação e as parcerias voltadas para os processos de criação, disseminação e uso dos conhecimentos coletivos.

Os fenômenos relativos ao compartilhamento da informação e do conhecimento em contextos organizacionais constituem vasto campo de estudo para pesquisadores das áreas de administração, ciência da informação, psicologia, comunicação, tecnologia da informação, dentre outras. Nesse sentido, argumenta-se que os múltiplos elementos que interferem - positiva ou negativamente - nos processos do compartilhamento da informação e do conhecimento são merecedores de estudos interdisciplinares para que assim consigamos aprofundar nossa compreensão dessas práticas e de suas contribuições para os resultados organizacionais.

Os resultados desses estudos poderão contribuir efetivamente para o aprimoramento dos princípios e práticas de GC corporativo. Uma das abordagens a ser aplicada no ambiente organizacional é a "governança do conhecimento", defendida por Foss (2007), que é justamente uma proposta que envolve diversas áreas do saber humano com o objetivo de tornar o conhecimento nas organizações um ativo de valor para o desenvolvimento das empresas e organizações em geral.

Artigo submetido em 13/09/2010 e aceito em 22/02/2011.

\section{REFERÊNCIAS}

ALCARÁ, Adriana R.; DI CHIARA, Ivone G.; RODRIGUES, Jorge Luis; TOMAÉL, Maria Inês; PIDADE, Valéria Cristina H. Fatores que influenciam o compartilhamento da informação e do conhecimento. Perspectivas em Ciência da Informação, v.14, n.1, p. 170-191, 2009. Disponível em http://www.eci.ufmg.br/pcionline/index.php/ pci/article/viewFile/721/545. Acesso em 29.08.09.

ALVARENGA NETO, Rivadávia C. Drummond. Gestão do Conhecimento nas Organizações: proposta de mapeamento conceitual integrativo. São Paulo: Saraiva, 2008. 236p.

BELL D. The coming of post-industrial society: a venture in social forecasting. New York: Basic Books; 1973. 507p.

BOWDITCH, James; BUONO, Anthony. Elementos do comportamento organizacional. São Paulo: Pioneira, 1992. 305p.

BROWN, J. S.; DUGUID, P. Organizational learning and communities-of-practice: towards an unified view of working learning and innovation. Organizational Science, v. 2, n. 1, p. 40-57, 1991.

CHOO, Chun Wei; BERGERON, Pierrette; DETLOR, Brian; HEATON, Lorna. Information culture and information use: an exploratory study of three organizations. Journal of the American Society for Information Science and Technology, v. 59, n. 5, p. 792-804, 2008.

COHEN, D. Towards a knowledge context: report on the first annual U.C. Berkeley Forum on Knowledge and the firm. California Management Review, v. 40, n. 3, p. 22-39, 1998.

CURRY, A.; MOORE, C. Assessing information culture: an exploratory model. International Journal of Information Management, $\mathrm{v}$. 23, n. 2, p. 91-110, 2003. 
Influências e barreiras ao compartilhamento da informação: uma perspectiva teórica

DAVENPORT, Thomas H. Ecologia da informação: por que só a tecnologia não basta para o sucesso na era da informação. 6. ed. São Paulo: Futura, 1998. 316 p.

DAVENPORT, Thomas H.; PRUSAK Laurence. Conhecimento empresarial: como as organizações gerenciam seu capital intelectual. Rio de Janeiro: Campus, 1998. 256 p.

DE LONG, David; FHAYER, Liam. Diagnosing cultural barriers to knowledge management. Academy of Management Executive, v. 14, n 4, p. 113-127, 2000. Disponível em <http://www.lostknowledge. com/pdfs/DeLong-DiagnosingCulturalBarriersToKnowlMgt.pdf $>$. Acesso em 03.08.09.

DRUCKER P. F. The age of discontinuity: guidelines to our changing society. Harper and Row, Publishers; 1969. 402p.

DYER, Jeffrey H.; NOBEOKA, Kentaro. Creating and managing a high performance knowledge-sharing network: the Toyota case. Strategic Management Journal, 21, p. 345-367, 2000. Disponível em <http://www3.interscience.wiley.com/cgi-bin/fulltext/71001350/ PDFSTART>. Acesso em 01.09.09.

FOSS, Nicolai J. The Emerging Knowledge Governance Approach: Challenges and Characteristics. DOI, v. 14; n. 29, p. 29-52, 2007.

HALL, Hazel. Input-friendliness: motivating knowledge sharing across intranets. Journal of Information Science, v. 27, n. 3, p. 139-146, 2001. Disponível em <http://jis.sagepub.com/cgi/ reprint/27/3/139>. Acesso em 03.09.09.

HENDRIKS, P. Why share knowledge? The influence of ICT on the motivation for knowledge sharing. Knowledge and Process Management, v. 6, n. 2, p. 91-100, 1999. Disponível em < http://mapule276883.pbworks. com/f/Why\%20share\%20Knowledge.pdf> / Acesso em 03.09.09.

HOLM, J. Capturing the spirit of knowledge management. Paper presented at the American Conference on Information Systems. Boston, MA., 2001. p. 2296-2300.

HUYSMAN, Marleen; WIT, Dirk de. Practices of Managing Knowledge Sharing: Towards a Second Wave of Knowledge Management. Knowledge and Process Management. published online in Wiley InterScience, v. 11, n. 2, p. 81-92, 2004. Disponível em <http://www3.interscience.wiley.com/cgi-bin/fulltext/109061403/ PDFSTART>. Acesso em 01.09.09.

IPE, M. Knowledge sharing organizations: a conceptual framework. Human Resource Development Review, v. 2, n. 4, dezembro, p. 337359, 2003. Disponível em <http://hrd.sagepub.com/cgi/ reprint/2/4/337>. Acesso em 30.08.09.

IVES, W.; TORREY, B.; GORDON, C. Knowledge Sharing is Human Behavior. Knowledge Management. Classic and Contemporary Works, D. Morey, M. Maybury and B. Thuraisingham, eds, MIT Press, Cambridge MA, 2003. 433 p. Disponível em < http://books. google.com.br/books?id=Ckb6GcUq31 MC\&dq=nowledge + Man agement: + Classic + and + Contemporary + Works\&printsec $=$ frontc over\&source $=$ bl\&ots $=$ drjxRxkEbr\&sig $=$ SF8BSQExImkBcLKYE xyHwRxG--U\&hl=pt-BR\&ei=wlPGSorjKsKruAfEnZ3bDg\&sa= $\mathrm{X} \&$ oi $=$ book_result\&ct $=$ result\&resnum $=2 \#_{\mathrm{v}}=$ onepage $\& \mathrm{q}=\& \mathrm{f}=\mathrm{tr}$ ue>. Acesso em 02.10.09.
KEONG, Lee Chu; AL-HAWAMDEH, Suliman. Factors Impacting Knowledge Sharing. Journal of Information \& Knowledge Management, v. 1, n. 1, p. 49-56, 2002. Disponível em < http:// link.periodicos.capes.gov.br/sfxlcl3?url_ver=Z39.88-2004\&url_ ctx_fmt=infofi/fmt:kev:mtx:ctx\&ctx_enc=info:ofi/enc:UTF8\&ctx_ver=Z39.88-2004\&rfr_id=info:sid/sfxit.com:azlist\&sfx. ignore_date_threshold $=1 \&$ rft.object_id $=111064855293000 \&$ svc. fulltext $=$ yes $>$. Acesso em 09.08.10.

KIM, Seonghee; JU, Boryung. An analysis of faculty perceptions: Attitudes toward knowledge sharing and collaboration in an academic institution. Library \& Information Science Research, v. 30, p. 282-290 2008. Disponível em < http://www.sciencedirect.com/science?_ $\mathrm{ob}=$ MImg\&_imagekey $=\mathrm{B} 6 \mathrm{~W} 5 \mathrm{R}>$. Acesso em 15.08.10.

LAM, A. Tacit knowledge, organizational learning and societal institutions: An integrated framework. Organization Studies, v. 21, n. 3, p. 487-513, 2000.

LECKIE, G. J.; PETTIGREW, K. E.; SYLVAIN, C. Modeling the information seeking of professional: a general model derived from research on engineers, health care professionals and lawyers. Library Quarterly, v. 66, n. 2, p. 161-193, 1996.

LIN, Hsiu-Fen. Effects of extrinsic and intrinsic motivation on employee knowledge sharing intentions. Journal of Information Science; v 33, n. 2, p. 135-149, 2007. Disponível em < http://jis.sagepub.com/ cgi/reprint/33/2/135>. Acesso em 01.09.09.

MARTIINEZ-SILVEIRA, Martha; ODDONE, Nanci. Necessidades e comportamento informacional: conceituação e modelos. Ciência da Informação, Brasília, v. 36, n. 1, p. 118-127, maio/ago. 2007.

NONAKA, I.; TAKEUCHI, H. Criação de conbecimento na empresa. Rio de janeiro: Campus, 1997. 358 p.

NOWAK, M.A.; K. SIGMUND, Shrewd investments. Science, p. 819-820, 2000.

OLIVER, G. Cultural dimensions of information management. Journal of Information \& Knowledge Management, v. 2, n. 1, p. 53-61, 2003.

ORNA, E. Making knowledge visible. Aldershot, Hants: Gower Publish, 2005. 208 p. Disponível em < http://books.google.com. $\mathrm{br} /$ books?id=MOLZssb5ewMC\&printsec $=$ frontcover\&dq $=\mathrm{m}$ aking + knowledge + visible\&source $=$ bl\&ots $=$ Z8VCSyTCqL\&sig $=$ s186kfYY9iiSQdfJrEuLxtPP5FQ\&hl=pt-BR\&ei=B2SBTJK $\mathrm{J} 4 \mathrm{SglAeDwdkv \& sa}=\mathrm{X} \& \mathrm{oi}=$ book_result\&ct $=$ result\&resnum $=1 \& \mathrm{v}$ ed $=0 \mathrm{CBkQ6AEwAA \#} \#_{\mathrm{v}}=$ onepage\&q\&f$=$ false $>$ Acesso em 03.09.09

PINTO, R.; CABRITA, I. TIC: produto, produtoras e provocadoras de mudança no contexto educativo. In P. Dias, e C. Freitas (Orgs.). Actas da $V$ Conferência Internacional de Tecnologias de Informacão e Comunicaşão na Educação: Desafios 2005/ Challenges 2005. Braga: Centro de Competência Nónio Século XXI, Universidade do Minho, p. 495-506, 2005. Disponível em: <http://repositorium. sdum.uminho.pt/bitstream/1822/10000/1/Cruz $\% 20 \% 26 \% 20$ Carvalho\%20-\%20SIIE-2009.pdf> . Acesso em: 25.08.10.

ROBBINS, Stephen, P. Comportamento organizacional. 11. ed. São Paulo: Pearson Prentice Hall, 1999. 536 p. 
SHANNON, Claude E. \& WEAVER, Warren. A teoria matemática da comunicação. 11. ed. São Paulo: DIFEL. 1975. 136p.

SHIN, Minsoo; HOLDEN, Tony; SCHMIDT, Ruth. From knowledge theory to management actice: towards an integrated approach. Information Processing and Management, p. 335-355, 2001. Disponível em <http://www.sciencedirect.com/science?_ ob=MImg\&_imagekey=B6VC8-4292GM8-9-1\&_cdi=5948\&_ user $=686413 \& \_$orig $=$search \&_coverDate $=03 \% 2 \mathrm{~F} 31 \% 2 \mathrm{~F} 2001 \& \_$ $\mathrm{sk}=999629997 \&$ view $=\mathrm{c} \& w \mathrm{wph}=\mathrm{dGLzVlz}-\mathrm{zSkWz} \& \mathrm{md} 5=73498$ $\mathrm{dd} 27 \mathrm{a} 3 f 9 \mathrm{~b} 82325 \mathrm{~d} 732 \mathrm{e} 43 \mathrm{c} 85513 \& \mathrm{kie}=/$ sdarticle.pdf $>$. Acesso em 25.09.09.

SIANES, Marta. Compartilhar ou proteger conhecimentos? Grande desafio no comportamento informacional das organizações. In: STAREC, Cláudio; GOMES, Elizabeth; BEZERRA, Jorge (orgs). Gestão estratégica da informação e inteligência competitiva. São Paulo: Saraiva, 2005. 351p.

SMALL, Cynthia T.; SAGE, Andrew P. Knowledge management and knowledge sharing: A review. Information Knowledge Systems Management, IOS Press, v. 5, n. 6, p. 153-169, 2006. Disponível em < http:// web.ebscohost.com $/$ ehost $/$ pdf ?vid $=5 \&$ hid $=104 \&$ sid $=94773 \mathrm{~d} 6 \mathrm{c}>$. Acesso em 31.08.09.

SPENDER, J.; GRANT, R. Knowledge and the firm: Overview. Strategic Management Journal, v. 17, p. 5-9, 1996.

STEWART, Thomas A. Capital intelectual: a nova vantagem competitiva das empresas. Rio de Janeiro: Campus, 1998. 237p.
WILSON, T. D. Human Information Behavior. Informing Science, v. 3, n. 2, p. 49-53, 2000. Disponível em <http://www.sciencedirect. $\mathrm{com} /$ science?_ob=ArticleURL\&_udi=B6VC8-3SX1FSW-B\&_ user $=10 \&$ _coverDate $=07 \% 2$ F 31\%2F 1997\&_rdoc $=1 \&$ _ $\mathrm{fmt}=$ high\&_orig $=$ search\&_sort $=\mathrm{d} \& \_$docanchor $=\& v i e w=\mathrm{c} \& \_$ searchStrId $=1336843417 \&$ \&rerunOrigin $=$ scholar.google $\&$ _ acct $=$ C000050221\&_version $=1 \& \_u r l V e r s i o n=0 \& \_u s e r i d=10 \& m$ d5=e0de6179f1f7be470775615063b780c3> . Acesso em 12.03.10.

Information Behaviour: An Inter-Disciplinary Perspective. British Library Research And Innovation Report, n. 10, 1997. Disponível em: <http://informationr.net/tdw/publ/infbehav/>. Acesso Em: 14. 03.2010.

On user studies and information needs. Journal of Documentation, v. 31, n. 1, p. 3-15, 1981. Disponível em < http:/ /www. emeraldinsight.com/Insight/Article/EmeraldFullTextArticle/20601. html>. Acesso em 15.03.10.

WOIDA, Luana Maia; VALENTIM, Marta Lígia Pomim. Cultura informacional voltada ao processo de inteligência competitiva organizacional: a relação entre as pessoas, a informação, e as tecnologias de informação e comunicação. VII ENANCIB - Encontro Nacional de Pesquisa em Ciência da Informação, GRUPO TEMÁTICO 4: Gestão de Unidades de Informação, p. 1-12, 4 de outubro de 2006. Disponível em <http://portalppgci.marilia.unesp.br/enancib/ viewabstract.php?id=248>. Acesso em 10.07.10.

YANG, Chyan; CHEN, Liang-Chu. Can organizational knowledge capabilities affect knowledge sharing behavior? Journal of Information Science, v. 33, n. 1, p. 95-109, 2007. Disponível em < http://jis.sagepub. $\mathrm{com} / \mathrm{cgi} /$ content/abstract/33/1/95>. Acesso em 17.07.10. 